\title{
Medical Procedure Services in Internal Medicine Residencies in the US: a Systematic Review and Meta-Analysis
}

\author{
Muhammad H. Hayat, MBBS ${ }^{\top}$ (D, Matthew H. Meyers, $\mathrm{MD}^{2}$, loannis A. Ziogas, $\mathrm{MD}^{3}$, \\ Majd A. El-Harasis, MD', Lawrence T. Heller, MD ${ }^{5}$, John A. McPherson, MD ${ }^{2,4}$, and \\ Kevin G. Buell, MBBS² \\ 'Division of Gastroenterology, Hepatology and Nutrition, Department of Medicine, Vanderbilt University Medical Center, Nashville, TN, USA; \\ ${ }^{2}$ Department of Medicine, Vanderbilt University Medical Center, Nashville, TN, USA; ${ }^{3}$ Division of Hepatobiliary Surgery and Liver Transplantation, \\ Department of Surgery, Vanderbilt University Medical Center, Nashville, TN, USA; ${ }^{4}$ Division of Cardiovascular Medicine, Department of Medicine, \\ Vanderbilt University Medical Center, Nashville, TN, USA; ${ }^{5}$ eepartment of Medicine and Public Health, Vanderbilt University Medical Center, \\ Nashville, TN, USA.
}

BACKGROUND AND AIMS: The number of procedures performed by internal medicine residents in the United States (US) is declining. An increasing proportion of residents do not feel confident performing essential invasive bedside procedures and, upon graduation, desire additional training. Several residency programs have utilized the medical procedure service (MPS) to address this issue. We aim to summarize the current state of evidence by systematically evaluating the effect of the MPS on resident education, comfort, and training, as well as patient safety and procedural outcomes in the US.

METHODS: We conducted a systematic review of all studies reporting the use of an MPS with supervision from a board-certified physician in internal medicine residencies in the US. Database search was performed on PubMed, Embase, ERIC, and Cochrane Library from January 2000 to November 2020 for relevant studies. Quality of evidence assessment and random-effects proportion metaanalyses were performed.

RESULTS: A total of nine studies reporting on 3879 procedures performed by MPS were identified. Procedures were safely performed, with a pooled complication rate of 2.1\% (95\% CI: 1.0-3.5) and generally successful, with a pooled success rate of $94.7 \%$ (95\% CI: 90.8-97.7). The range of procedures performed by residents under MPS was 6.7-72.8 procedures per month $(n=9)$ compared to 4.3-64.4 procedures $(n=4)$ without MPS. MPS significantly increased confidence, comfort, and use of appropriate safety measures among residents.

CONCLUSION: There are a limited number of published studies on MPS supervised by a board-certified physician in US internal medicine residencies. Procedures performed by MPS are generally successfully completed and safe. MPS benefits internal medicine residents training by improving competency, comfort, and confidence.

Received August 11, 2020

Accepted December 20, 2020

Published online Febnuary 5, 2021
KEY WORDS: meta-analysis; systematic review; medical procedure service; teaching; internal medicine residency.

\author{
Abbreviations \\ MPS \\ US \\ J Gen Intern Med 36(8):2400-7 \\ DOI: $10.1007 / \mathrm{s} 11606-020-06526-2$ \\ (c) Society of General Internal Medicine 2021
}

Medical procedure service United States

\section{INTRODUCTION}

Procedural training is an essential component of internal medicine residency and board-certified physicians are expected to be competent in invasive bedside procedures. ${ }^{1}$ Yet, an increasing number of residents do not feel confident performing core procedures, such as thoracentesis, paracentesis, lumbar puncture, and central venous catheterization. ${ }^{2}$ Education of physicians-in-training on bedside procedures has been shown to decrease preventable adverse outcomes ${ }^{3}$ and reduce the proportion of residents seeking additional training. ${ }^{4}$

Lack of supervision is the most commonly reported reason behind resident discomfort and dissatisfaction regarding their procedural training. ${ }^{5}$ Multiple interventions have been piloted to address training deficiencies. The first published account of a Medical Procedure Service (MPS) was from Beth Israel Deaconess Medical Center (Boston, MA) in 2002. ${ }^{6}$ MPS is an educational service where residents perform inpatient bedside procedures under the supervision of a board-certified physician. The use of MPS has subsequently spread to residency programs across the United States (US). ${ }^{6}$

It is hypothesized that an MPS improves patient safety and standardizes the approach to teaching, performing, and evaluating medical procedures. Yet, studies evaluating MPS procedural outcomes and the benefits on the procedural training of residents are limited. The aim of this systematic review is to characterize the types of procedures, safety profile, and educational benefit of MPS in US internal medicine residencies. 


\section{METHODS}

\section{Study Design}

The systematic review was conducted in accordance with the guidelines by the Preferred Reporting Items for Systematic Reviews and Meta-Analyses (PRISMA) (Appendix 1). ${ }^{7}$ The protocol was registered prospectively with the International Prospective Register of Systematic Reviews (PROSPERO 173296).

Full texts and abstracts published in English after January 1, 2000 , that reported the utilization of an MPS supervised by a board-certified physician in internal medicine residency programs in the US were considered eligible. Exclusion criteria included (i) non-English articles, (ii) studies structured without supervision of a board-certified physician, (iii) studies reporting on procedures in the outpatient setting, (iv) studies enrolling residents outside the US or in US residency programs other than internal medicine, (v) reviews (narrative or systematic) and meta-analyses, (vi) in vitro, animal, or genetic studies without any primary data, and (vii) book chapters, letters to the editor, errata, comments, perspectives, editorials that did not provide any primary data.

\section{Data Collection and Outcomes}

A standardized, pre-piloted form was used to extract data from the included studies. Two reviewers (MHH, MHM) extracted the data independently, and any disagreements were identified and resolved through quality control discussions with another author (KGB).

The outcomes of interest were the demographics of the residency program; level of training of the residents and supervising board-certified physician participating in the MPS; duration and structure of the MPS; duration of the study; presence and results of pre- and post-rotation competency; confidence assessments of residents on the MPS; scale used to measure resident's self-perceived knowledge and confidence; and success rate, complication rate, and type of complications of procedures performed by residents on the MPS. A successfully performed procedure was defined as having been completed during a single continuous attempt, regardless of the number of sites or procedure kits used.

\section{Search Strategy}

The search was carried out in PubMed, Cochrane, ERIC, and Embase (last search date: November 7, 2020). The search employed the following algorithm: "procedure training" OR "procedure service" OR "procedure teaching" OR "procedure education" OR "procedure elective" OR "teaching procedure" OR "bedside procedure" OR "medical procedure" OR "resident procedure" OR "procedural service" OR "procedural training" OR "procedural education" OR "procedural teaching" OR "procedural elective." Reference lists of the eligible studies were also systematically searched for relevant, potentially missed articles using the "snow-ball" approach. ${ }^{8}$ Two reviewers (MHH, MHM) independently screened the titles and abstracts, and then the full texts by applying the abovementioned inclusion and exclusion criteria. Disagreements were resolved through discussion with a third reviewer (KGB).

\section{Quality of Evidence Assessment}

The methodological quality assessment was performed independently by two reviewers (MHH, KGB), using the Downs and Black scale (Appendix 2). ${ }^{9}$ For the assessment of the observational studies, an adaptation was performed, as suggested by the Cochrane Collaboration, excluding items related to experimental studies $(7,9,14,15,16,17,24,26,27)$ because they did not fit the methodological design of the analyzed studies. Studies were classified as having high methodological quality when they presented scores $\geq 70 \%$ on the scale ( 15 points).

\section{Statistical Analysis}

Categorical variables were summarized as frequencies and percentages with the respective $95 \%$ confidence intervals (CI), and continuous variables as ranges. All relative rates were estimated based on available data for each variable of interest, and available data were handled according to the Cochrane Handbook principles. ${ }^{10}$

As most studies did not report on a comparison group, we conducted meta-analyses of proportions to calculate the pooled success rate and the total, lumbar puncture, paracentesis, thoracentesis, and central venous catheterization complication rates under MPS. Since the proportions in some studies were close to or exactly 0 or 1 , we transformed them into quantities according to the Freeman-Tukey variant of the arcsine square root-transformed proportion; otherwise, these studies would be excluded from the analysis, which would lead to a biased pooled estimate. ${ }^{11}$ Then, the pooled proportion was calculated as the back transformation of the weighted mean of the transformed proportions, using the randomeffects model to account for potential between-study clinical heterogeneity and to adopt a more conservative approach. The respective $95 \% \mathrm{CI}$ and the $p$ values were also calculated for each outcome. We assessed statistical heterogeneity among the included studies using $I^{2}{ }^{12}$ All analyses were performed using Stata IC 16.0 (StataCorp LLC, College Station, TX).

\section{RESULTS}

\section{Study Selection and Characteristics}

The search yielded 5684 articles, 13 of which underwent fulltext review. Nine studies (six full texts and three abstracts) were ultimately included in the systematic review. Six studies were rated as high methodological quality ${ }^{4,6,13-16}$ and three studies were rated as low methodological quality. ${ }^{17-19}$ Six studies reporting success or complication rates were included in the meta-analysis in the meta-analysis (Fig. 1). 


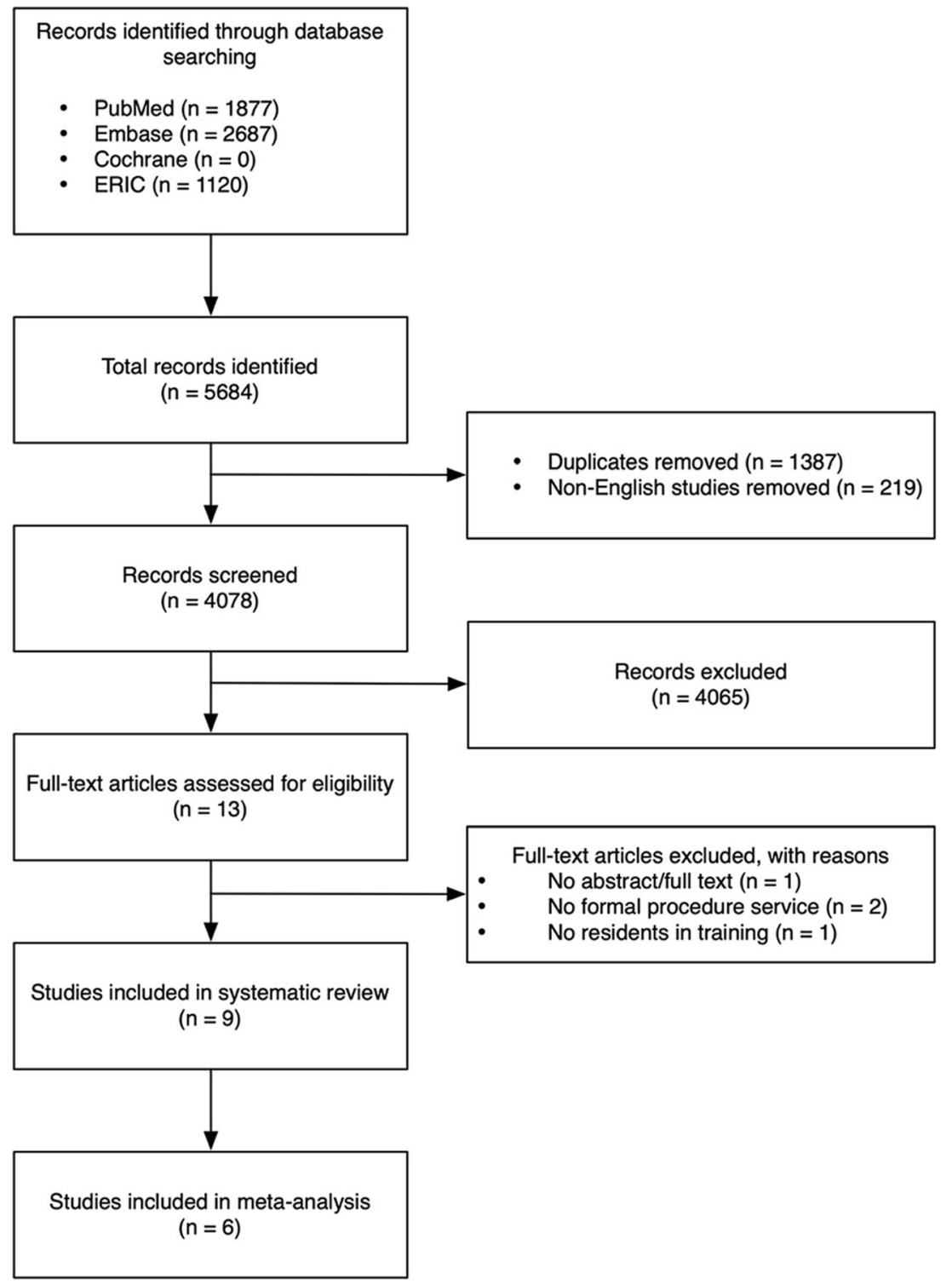

Figure 1 PRISMA (Preferred Reporting Items for Systematic Reviews and Meta-analysis) flow diagram of the search strategy and study selection.

Seven studies ${ }^{4,6,13-16}$ were carried out in university-based or university-affiliated academic programs. The MPS by Montuno et al. ${ }^{14}$ was part of a community residency program and Schmit et al. ${ }^{17}$ did not comment on the affiliation of their residency program. The study duration ranged between 3 and 48 months $(n=9)$. Table 1 summarizes the characteristics of the selected studies.

\section{Structure of MPS}

All studies enrolled internal medicine residents and one study ${ }^{4}$ also had participating medicine-pediatrics residents. The time that residents rotated on the MPS ranged between 2 and 4 weeks $(n=8)$. The number of residents per service ranged between 1 and $3(n=3) .{ }^{4,6,16}$ Board-certified instructors were pulmonary and critical care attendings or internal medicine hospitalists with specialized training in procedures. The board- certified physician in one study was a chief resident, ${ }^{17}$ while an advanced practitioner was present in addition to the boardcertified physician in another study. ${ }^{18}$

Resident education was supplemented with standardized didactic and simulation-based training in five studies using videos, three-dimensional models, and simulator-based practice. ${ }^{4,6,26,10,12}$ The didactics reviewed the indications, contraindications, risks, and benefits of all procedures, and basics of ultrasonography. Formal assessment after the supplemental training was conducted to assess the procedural competence of residents before performing bedside procedures on patients in three studies. ${ }^{6,15,17}$

\section{MPS Procedures}

All MPS supervised non-urgent procedures, while one study ${ }^{6}$ additionally included urgent procedures. Supervision was 
Table 1 Participant Characteristics in the Medical Procedure Service

\begin{tabular}{|c|c|c|c|c|c|}
\hline Study & $\begin{array}{l}\text { Duration of study } \\
\text { (months) }\end{array}$ & $\begin{array}{l}\text { Duration of MPS } \\
\text { (weeks) }\end{array}$ & $\begin{array}{l}\text { Board-certified } \\
\text { physician supervisor }\end{array}$ & $\begin{array}{l}\text { Total number of residents } \\
\text { enrolled in study }\end{array}$ & $\begin{array}{l}\text { Procedures performed by } \\
\text { MPS }\end{array}$ \\
\hline Smith 2004 & 12 & 4 & $\begin{array}{l}\text { PCCM attending } \\
\text { hospitalist }\end{array}$ & 139 IM residents & $\begin{array}{l}\text { Non-emergent and urgent } \\
\text { LP, PC, TC, CVC }\end{array}$ \\
\hline Lucas 2007 & 2 & 2 & Hospitalist & $16 \mathrm{IM}$ residents & $\begin{array}{l}\text { Non-emergent LP, PC, TC, } \\
\text { AC, CVC }\end{array}$ \\
\hline $\begin{array}{l}\text { Lenhard } \\
2008\end{array}$ & 11 & 2 & $\begin{array}{l}\text { PCCM attending } \\
\text { hospitalist }\end{array}$ & $\begin{array}{l}36 \text { IM residents } \\
3 \text { medicine-pediatrics } \\
1 \text { resident: NR }\end{array}$ & $\begin{array}{l}\text { Non-emergent LP, PC, TC, } \\
\text { CVC }\end{array}$ \\
\hline $\begin{array}{l}\text { Mourad } \\
2012\end{array}$ & 8 & 2 & Hospitalist & 16 IM residents & $\begin{array}{l}\text { Non-emergent LP, PC, TC, } \\
\text { CVC }\end{array}$ \\
\hline Chang 2012 & 3 & 2 & Hospitalist & NR & Non-emergent LP, PC, TC \\
\hline $\begin{array}{l}\text { Schmit } \\
2012\end{array}$ & 5 & 4 & Chief resident & NR & $\begin{array}{l}\text { Non-emergent LP, PC, TC, } \\
\text { CVC }\end{array}$ \\
\hline Tukey 2014 & 18 & 2 & $\begin{array}{l}\text { PCCM attending } \\
\text { hospitalist }\end{array}$ & NR & $\begin{array}{l}\text { Non-emergent LP, PC, TC, } \\
\text { CVC }\end{array}$ \\
\hline $\begin{array}{l}\text { Bakhru } \\
2015\end{array}$ & 24 & NR & $\begin{array}{l}\text { PCCM attending } \\
\text { advanced practitioner }\end{array}$ & NR & $\begin{array}{l}\text { Non-emergent LP, PC, TC, } \\
\text { CVC }\end{array}$ \\
\hline $\begin{array}{l}\text { Montuno } \\
2016\end{array}$ & 48 & 4 & $\begin{array}{l}\text { PCCM attending } \\
\text { hospitalist }\end{array}$ & $63 \mathrm{IM}$ residents & $\begin{array}{l}\text { Non-emergent LP, PC, TC, } \\
\text { CVC }\end{array}$ \\
\hline
\end{tabular}

Pulmonary and critical care medicine (PCCM); internal medicine (IM); thoracentesis (TC); paracentesis (PC); lumbar puncture (LP); central venous catheterization (CVC); not reported (NR)

offered for thoracentesis, paracentesis, lumbar puncture, and central venous catheterization in all studies, with the exception of one study, ${ }^{17}$ where central venous catheterization was not performed. One study ${ }^{4}$ also included supervised bedside arthrocentesis on the MPS. No study included the supervision of ultrasound peripheral vein cannula insertion, peripherally inserted central catheterization, nasogastric tube insertion, or surgical chest tube placement.

The number of procedures performed by residents under MPS ranged between 6.7 and 72.8 procedures per month $(n=$ 9 ). The number of procedures performed by residents without access to the MPS ranged between 4.3 and 64.4 procedures per month $(n=4) .^{13,15,16,19}$ All studies reported that residents performed more procedures independently after completing the MPS.

Three studies ${ }^{13,14,19}$ reported the number of procedures performed by residents before and after rotating on the MPS. In the study by Montuno et al., ${ }^{14}$ there were 4.3 procedures performed per month in the pre-MPS group vs. 6.7 procedures per month in the post-MPS group $(p<0.001)$. Chang et al. ${ }^{19}$ showed an increase in the number of procedures performed per month: 6.3 procedures per month pre-MPS vs. 34.7 procedures per month post-MPS implementation. In the crossover study by Lucas et al., ${ }^{13}$ the availability of the MPS increased the number of procedures from 61 to 90 procedures performed per 1000 admissions $(p=0.03$ ), and after crossover, the residents who lost the ability to utilize the MPS had a non-statistically significant drop in the number of invasive procedures they attempted independently.

Two studies reported findings of a MPS group and comparable control group. ${ }^{15,20}$ In the randomized control trial by Mourad et al., ${ }^{15}$ the MPS group performed more thoracenteses (median: 6 vs. $2 ; p<0.001$ ), paracenteses (median: 9 vs. 4 ; $p<0.001$ ), and lumbar punctures (median: 4 vs. $3 ; p<0.001$ ) compared to the control group. Similar findings were reported by Tukey et al., ${ }^{16}$ for thoracenteses ( 149 vs. $\left.72 ; p<0.001\right)$, but the regular service performed more paracenteses (127 vs. 163; $p<0.0001$ ), lumbar punctures (62 vs. $136 ; p<0.0001$ ), and central venous catheterizations ( 210 vs. $788 ; p<0.0001) .{ }^{16}$

\section{Procedure Success Rates}

The success rate of procedures was reported by four studies. ${ }^{13,16-18}$ The pooled success rate for all procedures was $94.7 \%$ (95\% CI: 90.8\%-97.7\%; $I^{2}=89.75 \%$ ) (Fig. 2a). Two studies compared the success rate between residents with and without access to the MPS. In the study by Tukey et al., ${ }^{16}$ MPS residents successfully completed more procedures $(95.8 \%$ vs. $92.8 \% ; p=0.02)$ and practiced better safety measures, including use of ultrasound guidance when appropriate and avoidance of femoral venous catheterization. In contrast, Lucas et al. ${ }^{13}$ reported no difference in the proportion of procedures completed successfully by residents where the MPS was available for consultation $(67 \%$ vs. $49 \% ; p=1.00)$ or for procedures with direct observation from the MPS physician (43\% vs. $73 \% ; p=0.64)$ compared to procedures where the MPS was not available.

\section{Procedure Complications}

The total complication rate for procedures performed by the MPS was reported in five studies (Table 2). ${ }^{6,13,15,16,18}$ The pooled total complication rate was $2.1 \%$ (95\% CI: $1.0-3.5 \%$; $I^{2}=72.79 \%$ ) (Fig. 2b). Three studies ${ }^{13,15,16}$ had no difference in the composite rate of major complications between MPS and regular service group. Two studies ${ }^{6,18}$ noted that procedures under MPS had complication rates consistent or lower than that reported in literature. ${ }^{20,21}$ All studies stated that the MPS resulted in an increase in the use of best practice safety measures.

Under MPS, lumbar punctures had the lowest complication rate with a pooled complication rate of $0.0 \%(95 \%$ 
a MPS: Success Rate

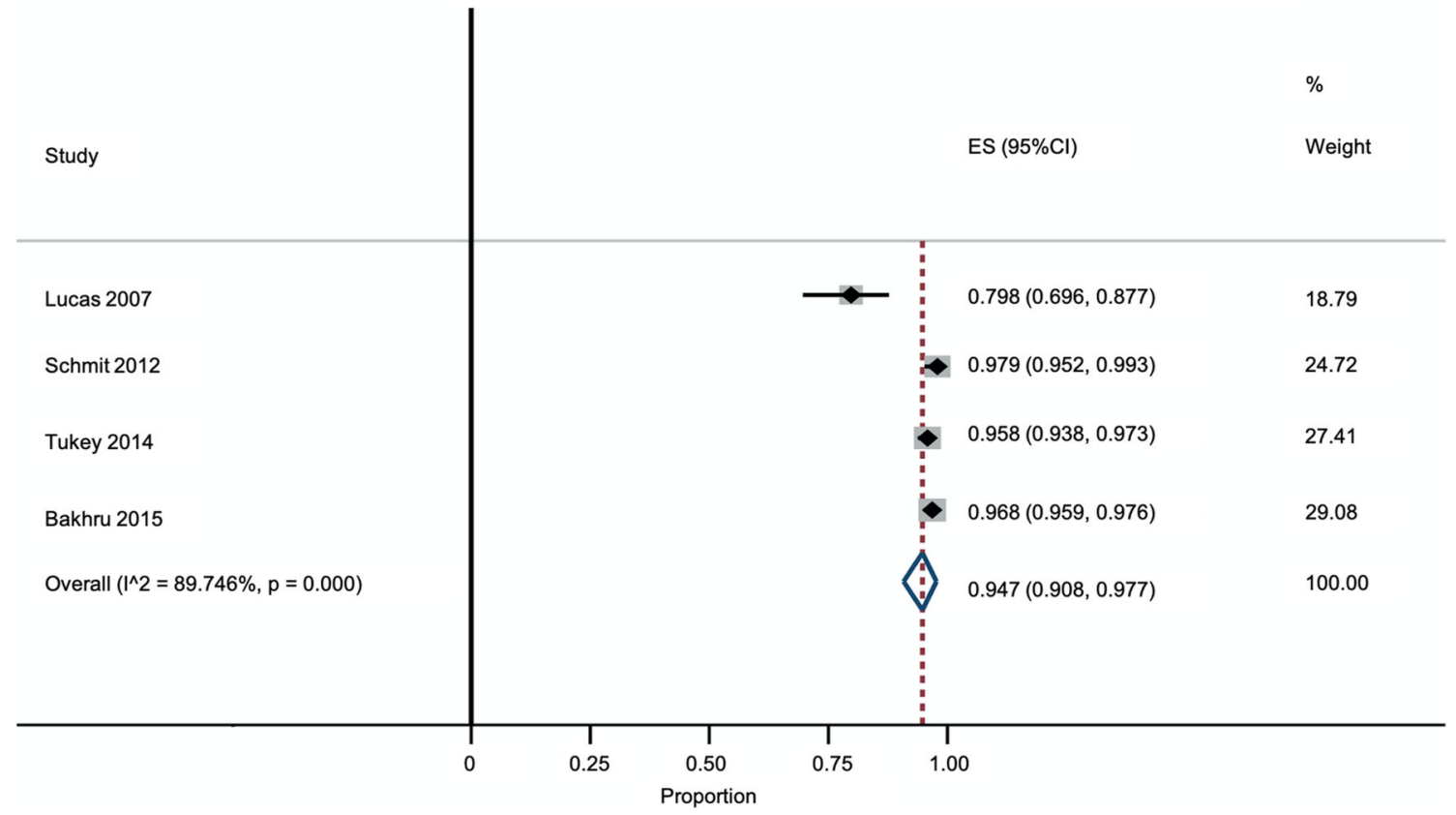

b

MPS: Total Complication Rate

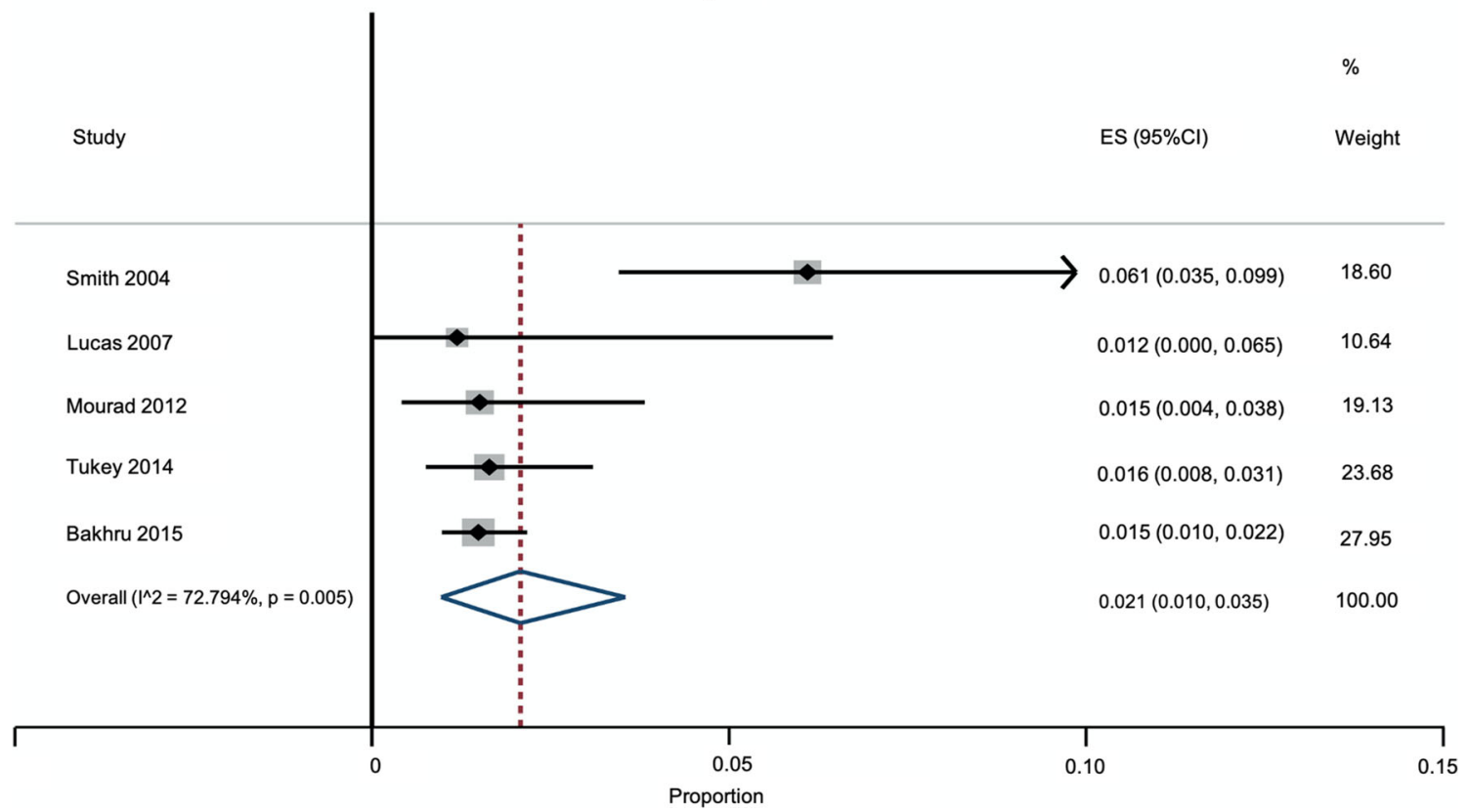

Figure 2 Forest plots reporting the pooled success rate (a), total complication rate (b). Random-effects modeling of pooled rates was used for the meta-analysis of proportions with $\mathbf{9 5 \%}$ confidence intervals.

CI: $0.0-1.3 \% ; I^{2}=00.00 \%$ ) (Fig. 3a). ${ }^{6,13,15,16}$ Paracentesis had the highest pooled complication rate of $2.3 \%(95 \%$ CI: $0.1-6.6 \% ; I^{2}=62.21 \%$ ) (Fig. 3b). ${ }^{6,13,15,16]}$ The pooled complication rate was $1.9 \%\left(95 \% \mathrm{CI}: 0.1-5.2 \% ; I^{2}=\right.$ $59.16 \%$ ) for thoracentesis (Fig. 3c) ( $^{6,13,14,16}$ and $1.9 \%$ (95\% CI: $\left.0.0-6.9 \% ; I^{2}=58.80 \%\right)$ for central venous catheterization (Fig. 3d). ${ }^{6,13,15,16}$

Two studies ${ }^{6,20}$ provided qualitative data on complications. Pneumothorax was the most commonly encountered complication during thoracentesis, accounting for $71.4 \%{ }^{6}$ and $66.7 \%^{16}$ of complications and resulting in an iatrogenic pneumothorax rate of $3.3 \%{ }^{6}$ and $4.0 \% .{ }^{16}$ Other less commonly encountered complications included hematoma, hemothorax, and infection. For paracentesis, hemorrhage was the most common complication, followed by failure to obtain ascitic fluid and kinking of the catheter. ${ }^{6,16}$ For lumbar punctures, Tukey et al. ${ }^{16}$ did not report any complications, while venous blood return requiring blood transfusion was the only complication reported by Smith et al.. ${ }^{6}$ 


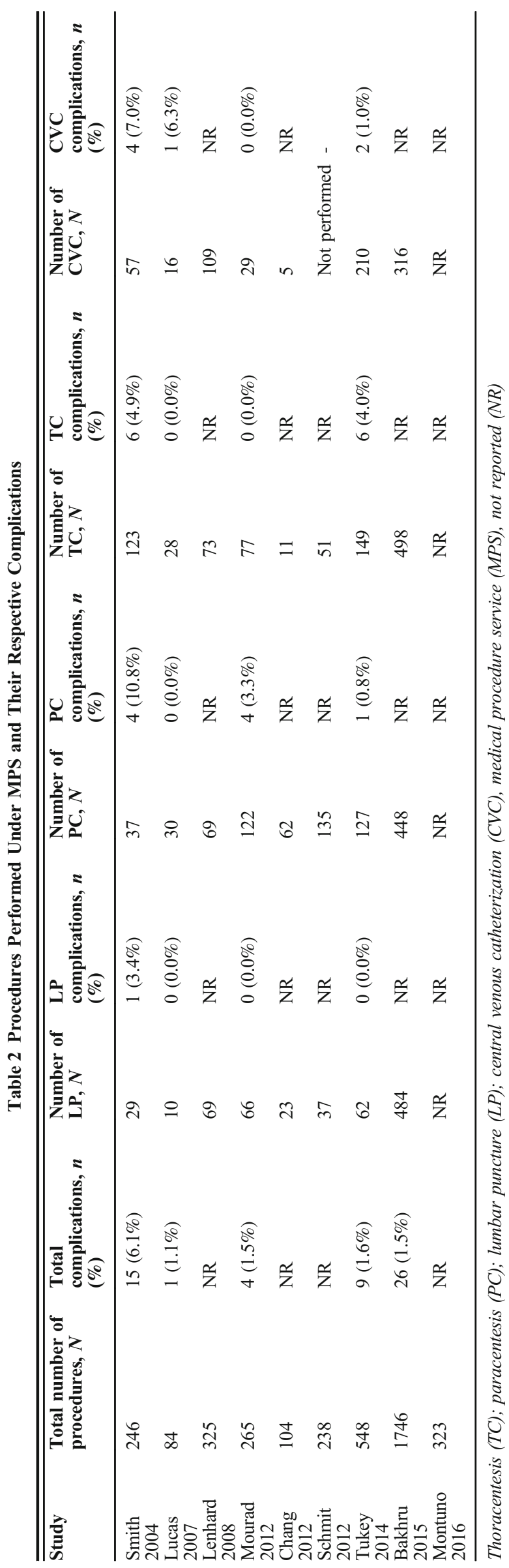

\section{Residents Confidence, Self-Perceived Knowl- edge, and Perspective}

Two studies reported on the confidence of residents performing bedside procedures before and after participation in the MPS. ${ }^{4,15}$ Residents in both studies felt significantly more confident after the MPS. In the study by Lenhard et al., ${ }^{4}$ the proportion of residents who felt comfortable increased by $15-36 \%$ for thoracentesis, paracentesis, lumbar puncture, and subclavian central line catheterization after participation in the MPS. Mourad et al. ${ }^{15}$ utilized a 5-point Likert scale and pre-MPS and post-MPS scores demonstrated an overall increase in confidence $(p<0.036)$ for thoracentesis ( 2.1 vs. 4.5 points), paracentesis (3.1 vs. 4.7 points), lumbar puncture (1.8 vs. 4.4 points), and central venous catheterization (1.8 vs. 2.9 points). Both before and after the MPS, residents felt least comfortable with central venous catheterization and most comfortable with paracentesis.

The same two studies ${ }^{4,15}$ reported on resident self-perceived knowledge prior to and after participation in the MPS. Residents in both studies rated their self-perceived knowledge higher after the MPS. Lenhard et al. ${ }^{4}$ used a five-point Likert scale to assess self-perceived knowledge on the use of ultrasound, sterile techniques, insertion technique, indications, complications, and management of complications. The median score increased by one point after the MPS $(p<0.001)$. Similarly, the resident self-perceived knowledge after the MPS in Mourad et al. ${ }^{15}$ was higher post-MPS than pre-MPS $(p<0.022)$ in the same categories, with troubleshooting as an additional category assessed.

Furthermore, Lenhard et al. ${ }^{4}$ reported that the desire for additional training among residents decreased by $26-51 \%$ depending on the type of procedure after the MPS rotation. Smith et al. ${ }^{6}$ found that of the residents who rotated on MPS, $87 \%$ felt that the MPS improved their knowledge of medical procedures, $90 \%$ believed the MPS helped prevent complications, and $83 \%$ rated the service as either time neutral or time saving. In two studies, ${ }^{4,15}$ the improvements seen in the knowledge, performance, and certification of residents after the MPS persisted into the next year of residency.

\section{DISCUSSION}

The MPS consisted of a hospitalist or pulmonary and critical care physician supervising non-urgent thoracentesis, paracentesis, lumbar puncture, and central vein catheterization. The majority of MPS incorporated didactic education and practice using mannequins prior to performing procedures on patients. ${ }^{4,6,15,17,19}$ Procedures were safely performed, with a pooled complication rate of $2.1 \%$, and generally successful, with a pooled success rate of $94.7 \%$. All studies stated that the MPS resulted in an increase in the use of best practice safety measures.

Over the past 30 years, the number of procedures performed by general medical practitioners has significantly decreased. ${ }^{22}$ 

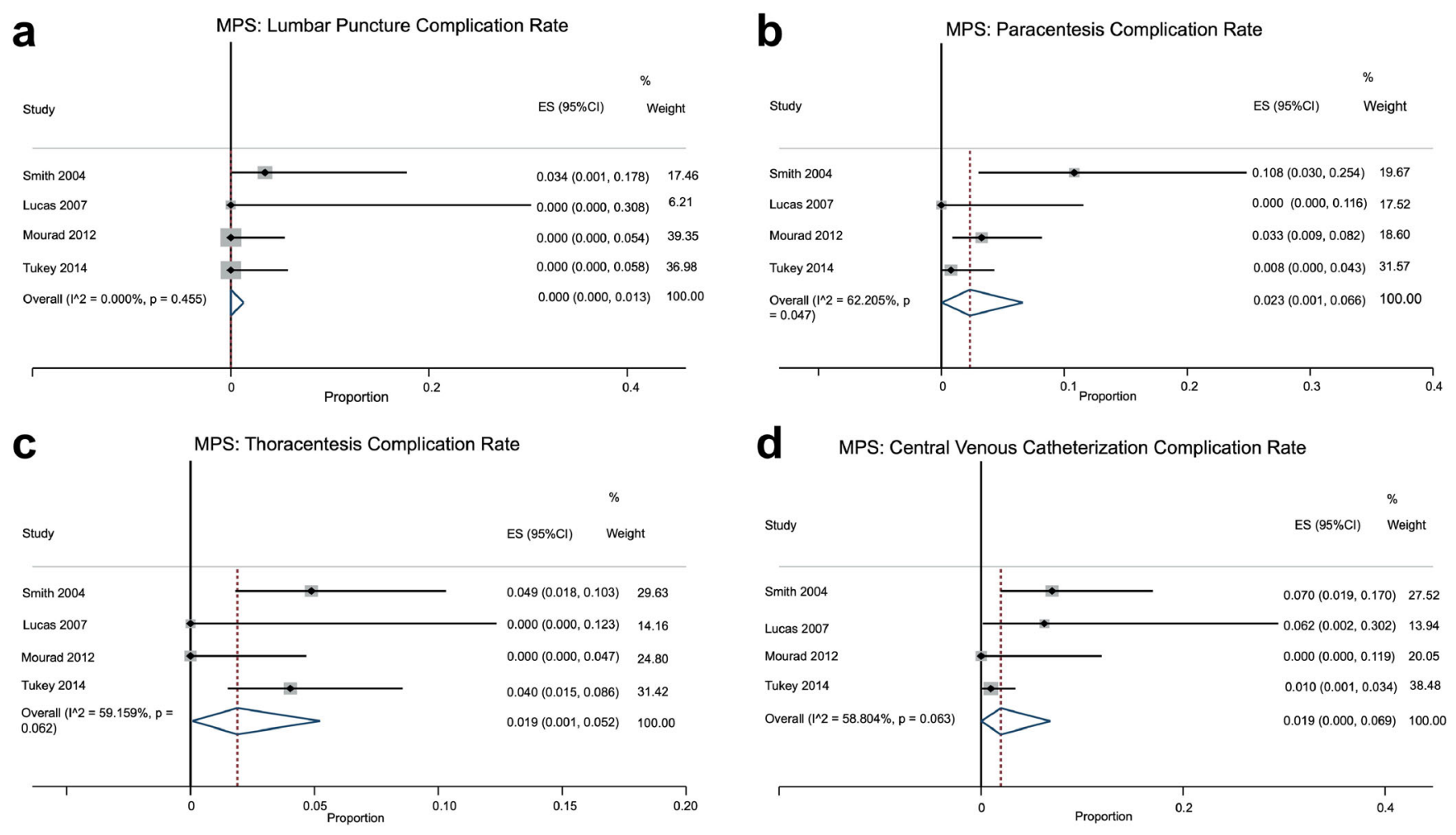

Figure 3 Forest plots reporting lumbar puncture (a), paracentesis (b), thoracentesis (c), and central venous catheterization complication rates (d). Random-effects modeling of pooled rates was used for the meta-analysis of proportions with $95 \%$ confidence intervals.

Effective 2007, the American Board of Internal Medicine removed the minimum requirement for the number of procedures performed by residents for board certification. ${ }^{23}$ Nine years later, Kay et al. ${ }^{24}$ reported that $84 \%$ of procedures encountered on a general medicine service at an academic medical center were referred and performed by a hospitalist or interventional radiologist.

The traditional "do one, see one, teach one" training model for procedures is a source of discontent among residents and program directors. ${ }^{25}$ Direct supervision has been shown to decrease procedural discomfort and the utilization of MPS as an educational tool for residents may represent a potential solution. ${ }^{5,26}$ All four studies that qualitatively assessed the educational experience of residents reported an increase in confidence and self-perceived knowledge. ${ }^{4,6,15,16}$ There is a growing body of evidence to support an increase in the number of procedures, certification rates, ${ }^{14,16}$ and overall procedural competence ${ }^{6,15}$ in residents participating in an MPS. Direct procedural supervision has also been linked to a reduction in complications. $^{3,27}$ The pooled complication and success rates for procedures performed by MPS were favorable compared to previous studies without MPS. ${ }^{24,28}$ Additionally, MPS led to an increase in the number of procedures performed by residents without an increase in complications. However, the results on risk reduction rates were discordant among the included studies.
To our knowledge, our study is the first systematic review to characterize the types of procedures, safety profile, and educational benefit of an MPS supervised by a boardcertified physician in US internal medicine residencies. As procedural competency and training requirements vary significantly between residents in internal medicine and nonmedical specialties, as well residents training in and outside the US, the inclusion and exclusion criteria were purposely designed to capture all studies from US internal medicine residencies. Our conclusions are consequently more specific, applicable, and likely to catalyze change within internal medicine residency programs across the US.

Limitations of our review include the retrospective nature of the majority of included studies, which impart a degree of inherent selection bias. There was considerable interstudy heterogeneity in study design, where only two studies included a contemporaneous control group ${ }^{15,16}$ and two other studies reported pre-MPS and post-MPS implementation outcomes. ${ }^{14,19}$ In addition, the subjective measurements of comfort and self-knowledge may not reflect competence. ${ }^{2,29} \mathrm{Fi}$ nally, our analysis grouped residents into one cohort due to the low number of included studies in our systematic review; our results do not assess the differences in procedural performance, comfort, and self-knowledge in relation to the resident training level.

With only nine studies meeting criteria for inclusion, the systematic review highlights the need for further research in 
this field. Future research should focus on additional factors that could be contributing to the broad uptake of MPS in US internal medicine residencies, the cost-effectiveness of MPS for procedural education, and an assessment of the durability of benefits derived from MPS.

\section{CONCLUSION}

There are limited published studies on MPS supervised by a board-certified physician in US internal medicine residencies. Procedures performed by MPS are generally successfully completed and safe. Procedural supervision by MPS results in an increase in the use of best practice safety measures. MPS benefits internal medicine residents training by improving competency, comfort, and confidence.

Supplementary Information The online version contains sup plementary material available at https://doi.org/10.1007/ s11606-020-06526-2.

Corresponding Author: Muhammad H. Hayat, MBBS; Division of Gastroenterology, Hepatology and Nutrition, Department of Medicine, Vanderbilt University Medical Center, Nashville, TN, USA (e-mail: muhammad.h.hayat.1@vumc.org).

\section{Compliance with Ethical Standards:}

All authors filled out a detailed Declaration of Interest Statement.

Conflict of Interest: The authors declare that they do not have a conflict of interest.

\section{REFERENCES}

1. Duffy FD, Holmboe ES. What procedures should internists do? Ann Intern Med 2007;146(5):392-3.

2. Hicks CM, Gonzalez R, Morton MT, Gibbons RV, Wigton RS, Anderson RJ. Procedural experience and comfort level in internal medicine trainees. J Gen Intern Med 2000;15(10):716-22.

3. Sherertz RJ, Ely EW, Westbrook DM, Gledhill KS, Streed SA, Kiger B, et al. Education of physicians-in-training can decrease the risk for vascular catheter infection. Ann Intern Med 2000;132(8):641-8.

4. Lenhard A, Moallem M, Marrie RA, Becker J, Garland A. An intervention to improve procedure education for internal medicine residents. J Gen Intern Med 2008;23(3):288-93.

5. Huang GC, Smith CC, Gordon CE, Feller-Kopman DJ, Davis RB, Phillips RS, et al. Beyond the comfort zone: residents assess their comfort performing inpatient medical procedures. Am $\mathrm{J}$ Med. 2006;119(1):71 e17-24.

6. Smith CC, Gordon CE, Feller-Kopman D, Huang GC, Weingart SN, Davis RB, et al. Creation of an innovative inpatient medical procedure service and a method to evaluate house staff competency. J Gen Intern Med 2004;19(5p2):510-3.

7. Liberati A, Altman DG, Tetzlaff J, Mulrow C, Gotzsche PC, Ioannidis JP, et al. The PRISMA statement for reporting systematic reviews and meta-analyses of studies that evaluate health care interventions: explanation and elaboration. Ann Intern Med 2009;151(4):W65-94.

8. Wohlin C. Guidelines for snowballing in systematic literature studies and a replication in software engineering. Proceedings of the 18th interna- tional conference on evaluation and assessment in software engineering, 2014. 1-10.

9. Downs SH, Black N. The feasibility of creating a checklist for the assessment of the methodological quality both of randomised and nonrandomised studies of health care interventions. J Epidemiol Community Health 1998;52(6):377-84.

10. Higgins JP, Thomas J, Chandler J, Cumpston M, Li T, Page MJ, et al. Cochrane handbook for systematic reviews of interventions: JohnWiley \&Sons; 2019.

11. Nyaga VN, Arbyn M, Aerts M. Metaprop: a Stata command to perform meta-analysis of binomial data. Arch Public Health 2014;72(1):39.

12. Higgins JP, Thompson SG, Deeks JJ, Altman DG. Measuring inconsistency in meta-analyses. BMJ. 2003;327(7414):557-60.

13. Lucas BP, Asbury JK, Wang Y, Lee K, Kumapley R, Mba B, et al. Impact of a bedside procedure service on general medicine inpatients: a firm-based trial. J Hosp Med 2007;2(3):143-9.

14. Montuno A, Hunt BR, Lee MM. Potential impact of a bedside procedure service on training procedurally competent hospitalists in a communitybased residency program. J Community Hosp Intern Med Perspect 2016;6(3):31054

15. Mourad M, Ranji S, Sliwka D. A randomized controlled trial of the impact of a teaching procedure service on the training of internal medicine residents. J Grad Med Educ 2012;4(2):170-5.

16. Tukey MH, Wiener RS. The impact of a medical procedure service on patient safety, procedure quality and resident training opportunities. J Gen Intern Med 2014;29(3):485-90.

17. Schmit $\mathbf{D}$, King $\mathbf{P}$, Velasquez $\mathbf{S T}$, Wathen $\mathbf{P}$. The design, implementation and impact of an internal medicine resident ultrasoundbased procedure service. J Hosp Med 2012;7:S121-S2.

18. Bakhru RN, Kotloff ED, Kinniry J, Lettieri M, Motley M, Jackson K, et al. Procedure outcomes and teaching by a formal inpatient procedure service. American Journal of Respiratory and Critical Care Medicine. Conference: American Thoracic Society International Conference, ATS. 2015;191(MeetingAbstracts)

19. Chang W, Popa A, DeKorte M. A medical invasive procedure service and resident procedure training elective. J Hosp Med 2012;7:S120.

20. Leape LL, Brennan TA, Laird N, Lawthers AG, Localio AR, Barnes BA et al. The nature of adverse events in hospitalized patients. Results of the Harvard Medical Practice Study II. N Engl J Med 1991;324(6):377-84.

21. Brennan TA, Leape LL, Laird NM, Hebert L, Localio AR, Lawthers AG, et al. Incidence of adverse events and negligence in hospitalized patients. Results of the Harvard Medical Practice Study I. N Engl J Med 1991;324(6):370-6.

22. Wigton RS, Alguire $\mathbf{P}$, American College of $\mathbf{P}$. The declining number and variety of procedures done by general internists: a resurvey of members of the American College of Physicians. Ann Intern Med 2007;146(5):355-60.

23. ABIM. American Board of Internal Medicine. Policies and Procedures for Certification. 2020. Accessed on November 24th , 2020 from: www.abim. org/ /media/ABIM\%20Public/Files/pdf/publications/certificationguides/policies-and-procedures.pdf.

24. Kay C, Wozniak EM, Szabo A, Jackson JL. Examining invasive bedside procedure performance at an academic medical center. South Med J 2016;109(7):402-7.

25. Fincher RM. Procedural competence of internal medicine residents: time to address the gap. J Gen Intern Med 2000;15(6):432-3.

26. Huang GC, Smith CC, York M, Weingart SN. Asking for help: internal medicine residents' use of a medical procedure service. J Hospital Med 2009;4(7):404-9.

27. Edwards T, Cook A, Salamonsen M, Bashirzadeh F, Fielding D. A combined hands-on teaching programme and clinical pathway focused on pleural ultrasound and procedure supervision transforms pleural procedure outcomes. Intern Med J 2017;47(11):1276-82.

28. Crocker JT, Hale CP, Vanka A, Ricotta DN, McSparron JI, Huang GC. Raising the bar for procedural competency among hospitalists. Ann Intern Med 2019;170(9):654-5.

29. Wigton RS. Measuring procedural skills. Ann Intern Med 1996; 125(12):1003-4

Publisher's Note: Springer Nature remains neutral with regard to jurisdictional claims in published maps and institutional affiliations. 